Educational Research for Social Change (ERSC)

Volume 10 No. 1 April 2021

pp. 52-69

ersc.nmmu.ac.za

ISSN: 2221-4070

\title{
Dithakga Tša Gobala: A Collaborative Book Creation Project ${ }^{1}$
}

\author{
Adrie Haese \\ ORCID No: http://orcid.org/0000-0001-8222-3010 \\ University of Johannesburg \\ ahaese@uj.ac.za
}

Elmarie Costandius

ORCID No: http://orcid.org/0000-0003-3561-7652

Stellenbosch University

elmarie@sun.ac.za

\begin{abstract}
A 2018 survey (Statistics South Africa, n.d.) reported that almost half of South African children aged four years had never read a book with their parents. In light of the current literacy crisis that South Africa is experiencing, providing appropriate materials to encourage and aid reading and storytelling activities is increasingly important but remains a challenge. Wordless picturebooks are an under researched literary genre in the South African context but, we argue, they can be used to spark a culture and love of reading because they can be enjoyed by readers of various backgrounds, language preferences, and literacy levels. Using participative research, the Dithakga Tša Gobala project investigated whether and how the development of wordless picturebooks in local communities could help parents engage in cognitively stimulating activities such as shared reading and storytelling. Stories sourced from two communities were used to create a series of wordless picturebooks that were then circulated in the communities. Initial results indicated that not only did the project have a positive impact on the participants' self-concept and their relationship with reading, but that the books were also positively received by the wider community. Results indicated that the books were easy to use, created positive parent-child experiences, encouraged imagination, and that the content of the books was relatable. Challenges that arose included issues of authorship and misunderstandings between authors and illustrators. Nevertheless, the findings suggest that wordless picturebooks are a valuable genre in the South African reading landscape and that a participatory model for creating relevant, local content for reading is not only viable but also beneficial for communities and other stakeholders.
\end{abstract}

Keywords: book creation, children's literature, illustration, reading, wordless picturebooks

Copyright: (C) 2021 Haese and Costandius

This is an open access article distributed under the terms of the Creative Commons Attribution NonCommercial License, which permits unrestricted non-commercial use, distribution, and reproduction in any medium, provided the original author and source are credited.

\footnotetext{
${ }^{1}$ Ethical clearance: Stellenbosch University Research Ethics Committee: Social, Behavioural and Education Research: Project number 7042
} 
Please reference as: Haese, A. and Costandius, E. (2021). Dithakga Tša Gobala: A Collaborative Book Creation Project. Educational Research for Social Change, 10 (1), 52-69.

http://dx.doi.org/10.17159/2221-4070/2021/v10i1a4

\section{Introduction}

The Statistics South Africa (n.d.) General Household Survey 2018 reported that almost half of South African children had never read a book or drawn with their parents by the age of four. In addition, $35 \%$ of surveyed households reported that they had never taken part in storytelling activities with their children. Statistics such as these are worrying because cognitively stimulating activities such as joint reading and storytelling support early or emergent literacy, and are fundamental in enabling early learning experiences that link to "academic achievement, reduced grade retention, higher graduation rates and enhanced productivity in adult life" (Strickland \& Riley-Ayers, 2006, p. 1). Activities such as shared book reading, which fosters early literacy, have been linked to the ability to maintain interest in reading, even when children can read without support (Meiers, 2004).

Considering the "national crisis of reading" (Spaull et al., 2016, p. 6) that South Africa is experiencing, providing appropriate and cost-effective reading materials to encourage and aid this activity is increasingly important but remains a challenge. Providing reading material for a culturally diverse audience that speaks 11 official languages and a variety of vernaculars is a difficult task. Both government and publishers are working with limited budgets in a context where reading materials, especially for younger children, are an expensive luxury for the majority of households.

This where our argument for the use of wordless picturebooks in the South African context comes in. Wordless books are books that create a story entirely, or predominantly, through pictures (Arizpe et al., 2014; Crawford \& Hade, 2000; Dowhower, 1997; Nikolajeva \& Scott, 2001; Serafini, 2014). Readers engage with the story by interpreting these pictures. The books allow multiple stories to be formed, using a language of the reader's choice. By emphasising visual literacy as a means to construct a narrative, the books can be read by readers of different literacy levels and do not rely on a person's ability to decode text or read in a specific language. The genre includes books of varying difficulty (Jalongo et al., 2002) and is appropriate for readers of all ages, ranging from basic picturebooks to complex graphic novels.

International literature on wordless picturebooks points to the widespread use of the genre in both educational and home settings (e.g., Arizpe, 2014; Dowhower, 1997; Jalongo et al., 2002; KnudsenLindauer, 1988; Reese, 1996). More recently, The International Board on Books for Young People (IBBY, 2020) has created a library of wordless picturebooks for use by refugees on the island of Lampedusa in Italy. The influx of refugees with different languages and cultures called for a new approach to engaging with them and introducing them to the language of their new home base (Lindfors, 2016). This led to the project, Silent Books: From the World to Lampedusa and Back, being launched in 2012. Hjorton and Corneliuson (2016) described this project as follows:

The project focused on a collection of wordless picture books, on the understanding that the inherent narrative power of the images could bridge cultural and linguistic barriers. Everyone could share in the same story, no matter where they came from or what language they spoke. (p. 2)

The IBBY Silent Books project also indicated that wordless picturebooks, through their ability to cross language barriers, provided a new way of working with displaced children. 
Little information exists on the use of the genre locally, although, due to the characteristics of the genre, it can be argued that these books are an ideal reading tool for South Africa's multilingual, multicultural landscape given that their reading is not limited to any language or literacy level. The few studies that are available indicate that wordless picturebooks have been positively received in instances where they have been introduced as a reading intervention (Arbuckle, 2004; Haese et al., 2018; le Roux, ${ }^{2}$ 2012, 2017; Schaffer \& Watters, 2003) and assessment tool (Acker, 2012). This is not to say that the genre is a solution to South Africa's literacy crisis but, rather, it can be seen as a tool to foster an engagement with books.

Literacy is often narrowly defined as the ability to read and write, or as being able to decode literary sounds (Guzula, as cited in eNCA, 2019). Literacy can be viewed in a much broader sense to refer to other competencies and skills that enable access to knowledge, for example, visual literacy or media literacy (United Nations Educational, Scientific and Cultural Organization, 2006). Guzula, a literacy expert from the University of Cape Town, highlighted that this narrow definition of literacy, which is perpetuated in South Africa, is "privileging children whose culture is in book reading" and that there is still a tendency to ignore storytelling resources that are available to children and parents (as cited in eNCA, 2019, 8:15). Wordless picturebooks require readers to create their own story through the interpretation of images and, as such, harness many of the benefits found in storytelling. Through listening to stories, children acquire an awareness of various forms of the written language. The National Association for the Education of Young Children (NAEYC, 1998) highlighted that the "talk" involved in storybook reading is powerful, allowing children to link events in the story to their own lives. This "decontextualized language" (Snow 1991, p. 5) can allow children to add their own imagination to what they can see in the story and, in this way, encourages higher-level thinking. Further, it can be argued that the wordless genre allows people from different backgrounds in the oral tradition of storytelling to enjoy book sharing, rather than focus on decoding text.

The characteristics of wordless picturebooks position them as a multimodal source of communication in that they require the decoding of meaning through an ensemble of modes rather than focusing on just one. Readers are required to interpret pictures (visual images) by telling a story (using words) that draws on their own cultural, historic, and social context. Multimodality in education has received renewed research attention during the last 15 years in South Africa. Williamson (2016) wrote that the acceptance of other communication means beyond language and writing ensures that children are able to move between many concurrent meaning-making opportunities.

\section{The Dithakga Tša Gobala Project}

\section{Aims and Objectives}

The focus of this study was not on the development of literacy as such but, rather, to investigate how the development of wordless picturebooks in local communities could foster a culture of reading or help parents engage in cognitively stimulating activates such as shared reading or storytelling, regardless of their literacy levels. Literacy is a contextual factor in the sense that the project works with people of differing literacy levels, although not measured as such. The objective of the study was to create a series of wordless picturebooks through a process of participation with local communities, which could be used by parents ${ }^{3}$ and children in shared reading, regardless of literacy levels or language choice.

\footnotetext{
${ }^{2}$ Le Roux is the maiden name of coauthor, Adrie Haese.

${ }^{3}$ In this article, references to "parents" include parents and caregivers.
} 


\section{Study Method}

The Dithakga Tša Gobala project-named by the participants who took part in the project in 2017loosely translates from Sesotho to mean "Reading Champions." Participatory research, as outlined by Bless et al. (2013), was used as the research design for this project. They described it as follows:

Participatory research encourages the active participation of the people whom the research is intended to assist. In this way it empowers people to be involved in all aspects of the project, including the planning and implementation of the research, and any solutions that emerge from the research. Everybody involved in the research project works together as a team (Bless et al., 2013, p. 90).

The population for the study was defined as parents or primary caregivers who resided in low socioeconomic areas, and their children, because parental involvement before school is an extremely important aspect of teaching children a love for reading and books - and a predictor of later academic success (Acker, 2012). Purposive sampling was used to select participants at the two research sites with the initial aim of involving six parents and their children at each site. Because the research was to be facilitated from the selected early childhood development (ECD) centre or school, parents needed to have a child enrolled at that institution. In 2017, six adults and their children, aged between three and six years old, took part in the project at the Mamelodi site. In 2018, five adults took part in the project at the Mamelodi site, and six adults and their children, aged between seven and nine years, took part at the Danville site. It should be noted that although sampling at the Danville site was based on the child's enrolment at the school, the participants extended the project to their families with the result that, in some cases, authorship for each book is attributed to an entire family rather than to only one adult and one child participant. Adults were not always the child's biological parents but sometimes an aunt, uncle, or sibling who took part in the project with their relative (child). Table 1 provides an outline of the participants per year.

\section{Table 1}

\section{Detail of Participants in the Study}

\begin{tabular}{lll}
\hline Year & Mamelodi & Danville \\
\hline 2017 & $\begin{array}{l}6 \text { adults } \\
6 \text { children (aged 3-6 years) }\end{array}$ & Project did not run \\
& 5 adults & \\
\hline 2018 & adult mentors & 6 adults \\
& 6 children (aged 7-9 years)
\end{tabular}

Bless et al. (2013) noted that the first step in participatory action research (PAR) is the request for assistance, which should ideally come from the community. The community was approached with the idea to collaboratively explore the ways in which communities could provide their input into the creation of picturebooks and to participate in the evaluation of the use of the books. The research sites at which the project was run were identified as existing in communities characterised by poverty and low socioeconomic status because there is an obvious link between illiteracy and poverty (Mahala, 2010), and low literacy levels are often linked to lack of exposure to books. In 2017, the project only ran in Mamelodi East in Tshwane, and was based at an ECD centre. Corporate funding was received for this project in 2017. In 2018, with continued corporate funding and additional funding received from the National Research Foundation (NRF), the project was continued in Mamelodi East and was extended to a primary school in Danville, also in Tshwane. 
Both of the selected sites offered social work and family support services and were well established in the surrounding community. Consequently, they were seen as an appropriate contact point for the project to invite members of the community to participate in the project given that social workers could be used as gatekeepers for the research. It should be noted that, as a means to ensure transparency, the project was run through a registered nonprofit/public benefit company. This would provide a clear picture to all funders of how funds were used. ${ }^{4}$

After an introduction session in which community members learnt about the project and its aims, community members (see Table 1) volunteered for the project. During the negotiation phase of the PAR (Bless et al., 2013), a working relationship was established with all participants. The participants brought to the table active participation, first-hand knowledge and experience of reading and storytelling in their community, and knowledge of what content their children might enjoy reading. The researchers provided theoretical knowledge on wordless picturebooks, access to illustrators and the materials resources, and physical space to complete the project. During an initial focus group session, the long-term goal of the project was identified by 2017 participants as encouraging a culture of reading in their community and the name, Dithakga Tša Gobala (reading champions), was chosen to identify the books created through the process. It was decided to keep this name for the project.

The planning phase (Bless et al., 2013) outlined how we would work together to meet the goals of the project. Project timelines, the formats of workshops, and times and places that we would meet were decided and agreed in the group at the start of the 2017 and 2018 projects. Roles and decision-making capacity were also discussed in detail, and it was emphasised that the decisions made by community participants were integral to each process of the book creation project. These decisions pertained to how their story was recorded (drawing, writing, voice recording, singing, video recording), how the illustrators represented their stories, and how the final books were distributed.

Once this had been done, the project was implemented. The data collection process for the creation of the books can be described as comprising of three distinct phases: story collection, illustration, and feedback. Each phase included a set action and reflection on that action, and the process was iterative and reciprocal. Table 2 lists the dates of each project phase during 2017 and 2018 and is followed by an outline of the phases.

\footnotetext{
${ }^{4}$ Company financials are available online or upon request.
} 
Table 2

Project Phases and Dates

\begin{tabular}{lccc}
\hline Project phase & Mamelodi 2017 & Mamelodi 2018 & Danville 2018 \\
\hline Introduction and planning & 20 April & 27 March & 13 April \\
\hline $\begin{array}{l}\text { Story collection workshops } \\
\text { Feedback on illustration roughs and } \\
\text { story outline }\end{array}$ & $\begin{array}{l}\text { 6 May } \\
\text { 1 June }\end{array}$ & 3 May (afternoon) & 3 May (morning) \\
\hline $\begin{array}{l}\text { Feedback on colour pages and } \\
\text { detailed planning }\end{array}$ & 12 April & 17 April \\
\hline $\begin{array}{l}\text { Final sign-off and distribution } \\
\text { planning }\end{array}$ & 1 August & 31 May (afternoon) & 31 May (morning) \\
\hline \begin{tabular}{l} 
Book launch \\
\hline
\end{tabular} & 31 August & 30 August & 2 August \\
\hline
\end{tabular}

\section{Story Collection}

The participants were asked to attend two story collection workshops. The data (stories) collected from these workshops would be sent to illustrators who were tasked with the illustration of a 16-page wordless book based on the stories.

The workshops were structured in a manner that allowed parents and children to work together to create a story. The participants were invited to draw, write, dance, sing, or use voice recordings or any other media of their choice to document their story in a language they were comfortable speaking. The researcher and a social worker on site facilitated the workshops, which took place over the space of two days. They reiterated the goals of the workshops and ensured that participants had access to any materials they needed to document their stories. Translators were available for participants who did not speak English and any written material that was not in English was translated.

Once the participants started engaging with their chosen media, stories seemed to be easy to tell and document and the participants also indicated what type of images they would like to see in their book. Both parents and children created visual reference material for the illustrators to use, as seen in Image 1. At the end of the two workshops, the facilitator checked that her understanding and interpretation of the collected data were correct and that she would be able to brief the illustrators effectively. 


\section{Image 1}

Images From the Story Collection Workshops in Which Parent and Child Participants Are Engaged in Creating Visual Reference Materials for Use by Illustrators (2018)
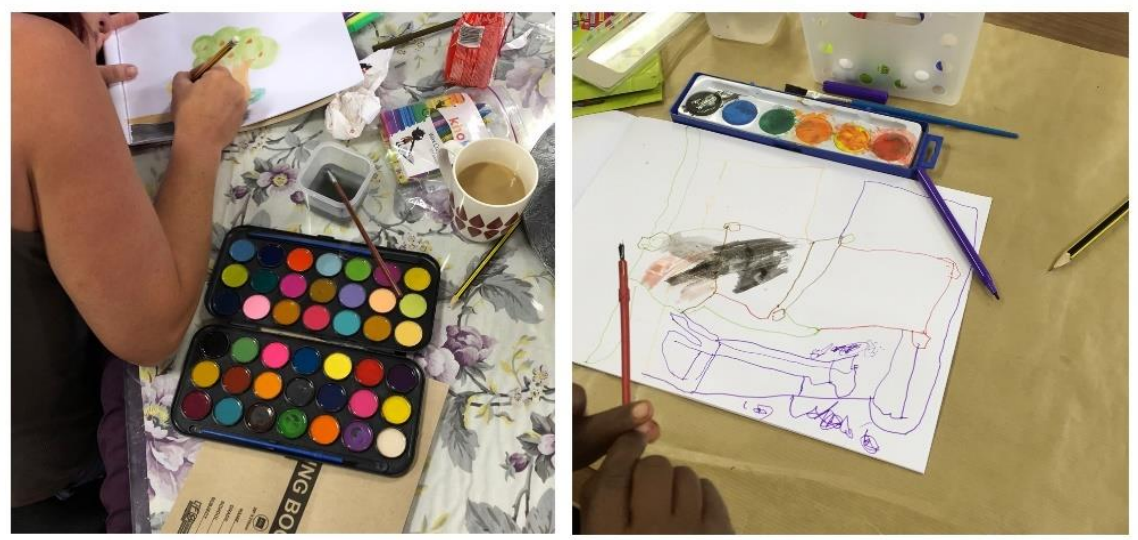

\section{Illustration and Feedback}

The data pertaining to the collected stories (writing, voice recordings, video recordings) were transcribed by the researcher and sent to the illustrators along with any references provided by the concept authors. Image 2 shows some of the material collected from concept authors during the workshops. A number of final-year illustration students and professional illustrators worked on the project.

Data collected from the workshops ranged from being very specific about the details of the story and its representation to being very open to interpretation. The illustrators were asked to provide work in three phases. After each phase, a feedback session was arranged with the participants to make sure that their story was being depicted in a manner with which they were happy. 


\section{Image 2}

Examples of Visual Reference Material Created by Concept Authors. These Were Sent to Illustrators To Use in the Planning of the Final Books (2017-2018)
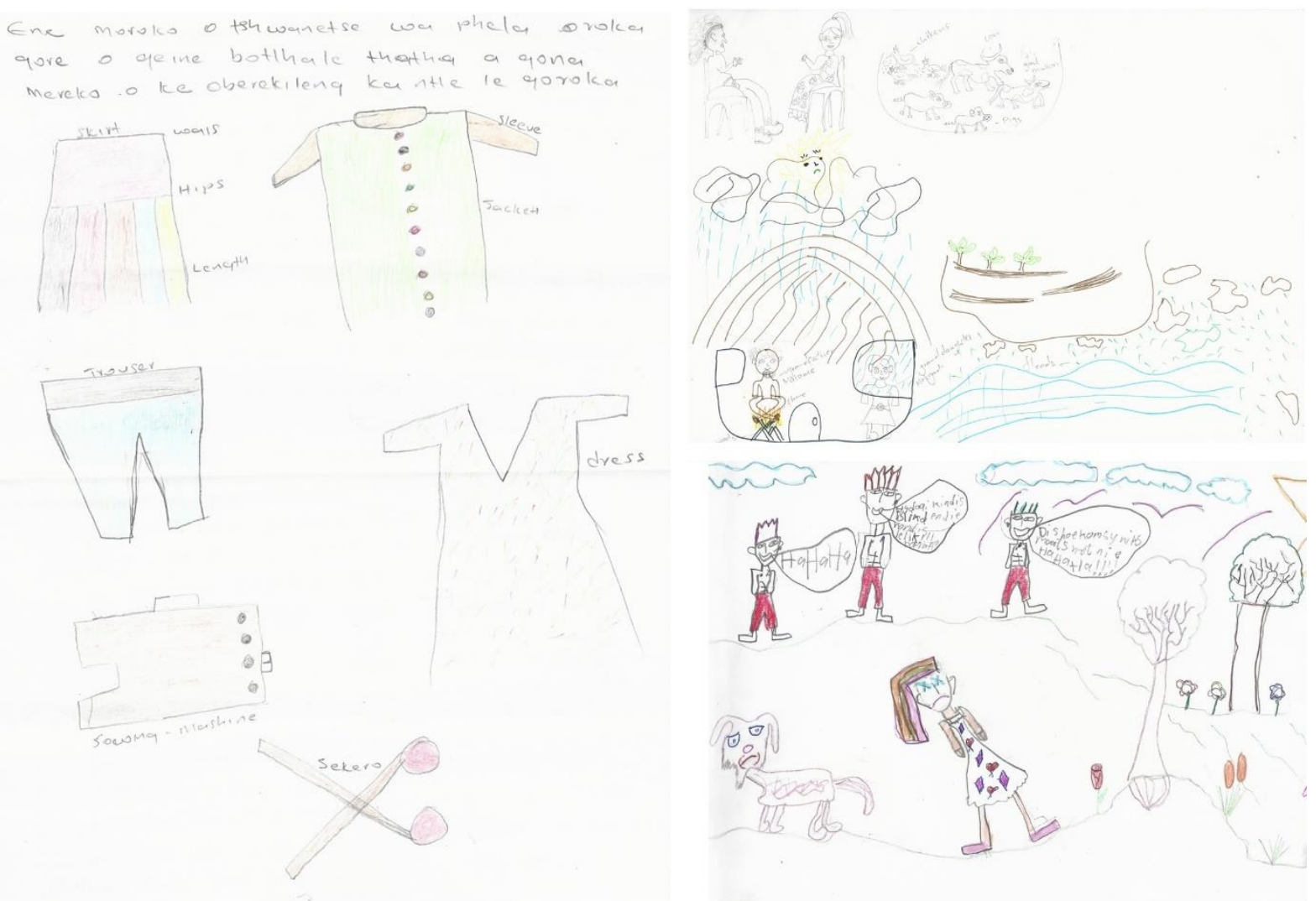

The first stage of the illustration process was the illustration roughs and story outline stage. The illustrators provided the 16-page story outline with an explanation of what action would take place on each page. In addition, they worked on character development and a colour scheme for the book. Examples of the illustration roughs are shown in Image 3. This work was printed and taken to each research site for feedback from the participants. Changes were indicated verbally or on the printed pages themselves and then communicated to the illustrators who implemented the changes before their next deadline. 


\section{Image 3}

Examples of Illustration Roughs That Were Used in Phase One of the Book Creation. These Roughs Were Printed and Given to the Concept Authors, Who Were Invited To Make Suggestions and Changes to the Work Before the Illustrators Continued Working on the Books (2018, from left to right, Zinhle Zulu, Stephen Wallace, le Roux)
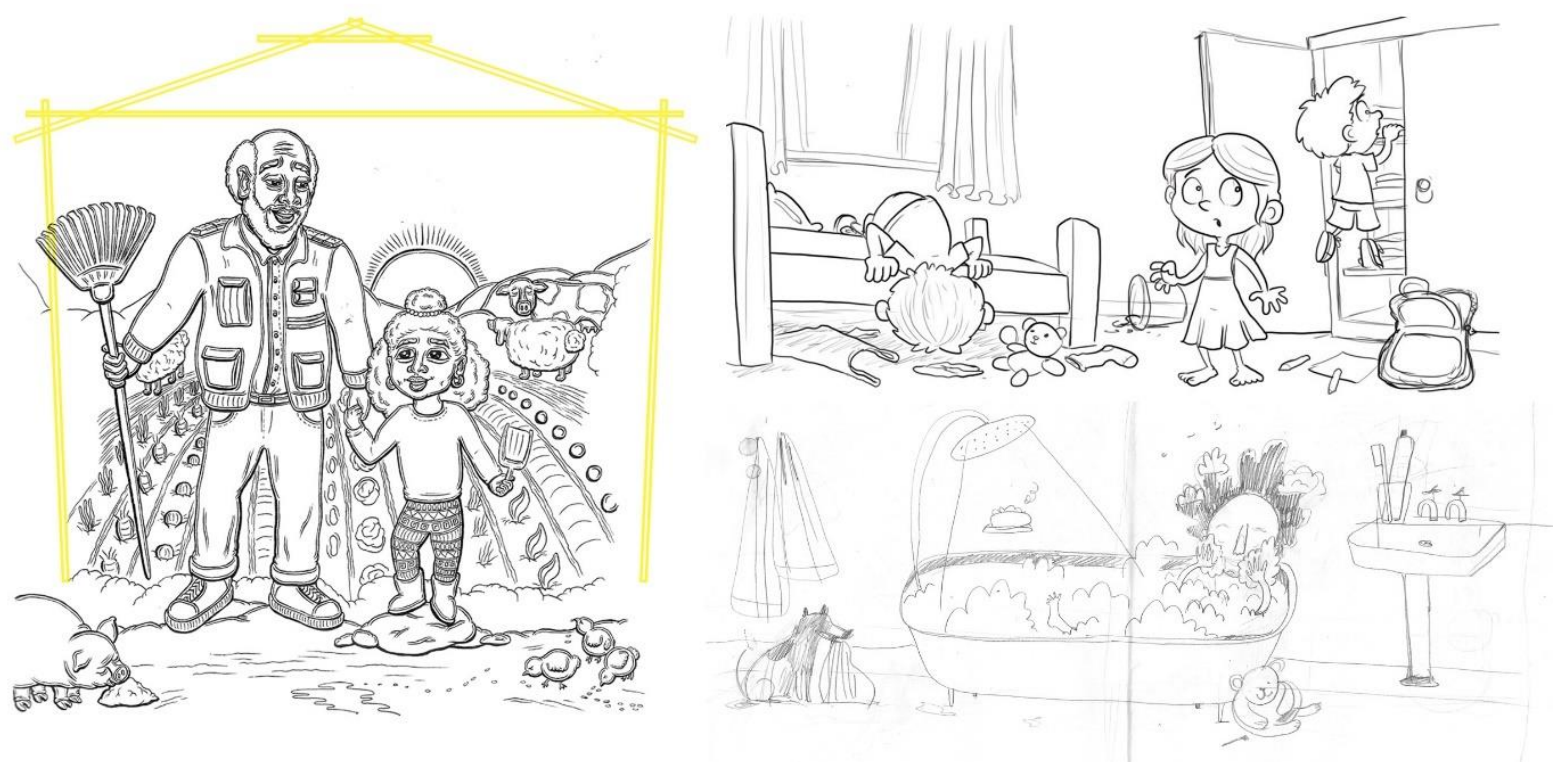

The next stage was for the illustrators to provide several final colour pages and detailed planning on the rest of the book. Image 4 shows examples of colour pages provided to concept authors. The participants were again invited to give feedback on this stage during a feedback session. Lastly, the illustrators provided a final copy of the illustrated story. Concept authors were asked to suggest any final changes they would like made and to then sign off on the book if they were happy with the final product.

\section{Image 4}

Examples of Colour Pages Given to Concept Authors for Comment Before the Illustrations Were Finalised (2018, from left to right: Jess Jardim-Wedepohl, le Roux)
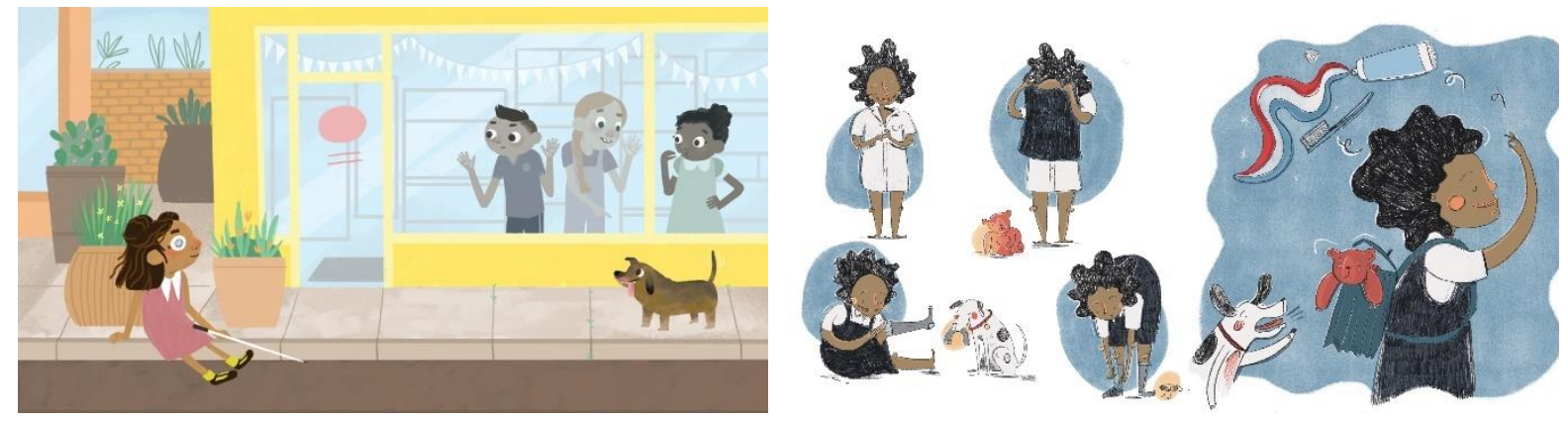

Final Product and Distribution

In 2017 and 2018, the project resulted in the creation of 16 wordless picturebooks. Pages from these are shown in Image 4. The books were open-licensed under a Creative Commons Attribution 4.0 License, which allowed for the concepts and illustrations to be shared and adapted for any purpose, provided the original author and illustrator were credited for their work. E-books were made available on a web platform and print files could be requested via the website. 
In addition to the e-books, the researchers circulated a number of printed copies to the participants, the surrounding community, reading organisations, schools, and other nonprofit organisations. The participants were actively involved in decisions pertaining to how the books would be made available, and these decisions were made as part of a team.

\section{Data Collection After Distribution of Books}

After the conclusion of the project, data pertaining to participant experience of the project were collected from the participants (authors) through semi-structured group or individual interviews based on the availability and preference of participants at each research site.

Data on the use of the books in the community were collected from parents with children registered in the ECD class of the Mamelodi site because every family had received a book pack containing all the books created during that project year to take home. Data were collected using feedback forms that were filled out with the assistance of care workers employed at the centre. The care workers included the completion of the form as part of their home visits. Data were analysed using thematic analysis, defined by Braun and Clarke (2013, p. 120) as "a method for identifying and analysing patterns in qualitative data."

Various methods were used to ensure the trustworthiness of the study. Peer debriefing (Guba, 1981) was done with the support from social work professionals at the research sites who were willing to provide professional opinions on the data collected. Triangulation was established by using different data collection methods (Shenton, 2004), which included group interviews and individual interviews, feedback forms, as well as the visual and written data collected from the story collection workshops. Member checking was done both during and at the end of interviews (Guba, 1981; Shenton, 2004). These checks served to ensure that the researcher was correctly interpreting what the participant was saying. Participants could listen to their interviews and request a transcript for their records if they wished.

\section{Ethical Considerations}

Protocols set up to ensure ethical facilitation of the project included participants being approached through gatekeepers. Singh and Wassenaar (2016) noted, "Conscientious and well-informed negotiations with gatekeepers are required in order to honour the ethical obligations to conduct appropriate stakeholder engagement before and during research, along with respect for the autonomy of institutions and their employees/clients/service recipients" (p. 45).

A social worker based at each research site served as gatekeeper between researcher and participants and made contact with potential participants before the researcher did. Consequently, the voluntary nature of the study was emphasised and participants also had someone to speak to if they wished to withdraw from the research or were unhappy with any aspect of the project. Similarly, the researchers acted as facilitators between the concept authors and illustrators. In this way, we hoped to allow concept authors to give their honest feedback on the illustrations without fear of offending the illustrator.

Participation in this project was voluntary, and the participants were free to withdraw from the project at any time with no negative consequences. Informed consent was given by all participants, and children and their parents were required to sign assent forms. Because the books were made available publicly, the participants could choose to have their names appear on the cover and copyright information of the book, or they could choose to remain anonymous. 
Where participant names would appear on the books, responses in any reports were coded to keep individual answers, opinions, and feedback confidential. The participants were all aware that reports on the project would be written, and gave consent for their responses to be used. Contributor forms were signed by all project participants, which allowed the books to be open-licensed. All participants were made aware of the implications of this and agreed that their stories, concepts, and illustrations could be used by the project in this manner. Institutional clearance for the 2018 project was granted from Stellenbosch University. The 2017 study did not go through any formal ethical clearance procedures because it was implemented outside the university context as a follow up of a doctoral study (le Roux, 2017). However, the same ethical principles that governed le Roux's (2017) study were followed, and all forms were developed with the assistance of social workers based at the research sites.

The reciprocal and iterative nature of the project served to strengthen the collaborative relationship between researchers, participants, and illustrators. Continual feedback loops were created in which participants were empowered: their opinions were respected, the changes that they recommended to illustrations were implemented, and their vision for the project became integral the process. The empowering nature of collaboration is confirmed in the research findings in reports on participant experience of the project.

The collaboration also led to the shared ownership of the books produced during the project. All stakeholders have the right to use and share the books. The books, in this sense, can be viewed as new knowledge. The addition of a unique ISBN number registered with the National Library of South Africa and the stipulation that the concept author, illustrator, and project name must always be credited in any adaptation of the work, serve as recognition given to new knowledge made by communities.

\section{Discussion of Findings}

The project's first year concluded in November 2017. Based on suggestions from project participants and the community, the project continued in 2018 with participants from 2017 taking the lead as mentors for new authors and managing the project. Other suggestions from the community included the continuation of the project into reading material for older children, the establishment of book clubs (with training for facilitators), and that the concept authors be supported in the creation of more storybooks.

The discussion below is divided into two sections in order to report on data and feedback collected during the project while the books were being completed, and after the completion of the project when books had been printed and distributed to concept authors and the community. Data collected after the completion of the project are further divided into data from the participants who took part in the book creation project and the community who received copies of the books-although they were not directly involved in the creation of them.

\section{Feedback during the project}

During feedback sessions where the illustration roughs and colour roughs were presented, the participants added personal touches to their story, for example, requesting that their child's favourite toy be included in a scene. One participant asked for major changes to the illustrations, indicating that she felt the illustrations were not relevant to her community or might easily be misunderstood. She explained that it would not be easy for her to talk about a concept such as space travel, and it would be easier to talk about illustrations that were more relevant to her daily life. 
Issues of authorship were also raised during the development of the wordless books. Stories collected were sometimes incomplete or lacking detail, resulting in the illustrators taking initiative in constructing scenes or adding detail to create a more complete storyline for their book. This brought the illustrators' voice into the story with the result that the books can be viewed as more of a collaboration than a direct representation of community stories. The participants were asked to provide feedback on illustrator suggestions. Although all the books were given final sign-off, power relationships may have caused participants to feel that they could not say what they really wanted to because the illustrators had already suggested a solution. Issues of authorship also had to be navigated in cases where illustrators felt that they should also receive credit for the story, and not only be listed as illustrator.

Although limited to two instances, the project also highlighted the sensitivity with which illustrators needed to approach the narratives provided by the authors. In these instances, there were significant differences between the illustration roughs and the final illustration. The authors reported that they were "sad" when they saw the changes, and that they had thought the illustrations would look like the ones they were shown during the planning phase-which should have been the case. Facilitator efforts to mediate this resulted in illustrators feeling that they had lost their creative voice, while authors felt that their stories were not being depicted in the manner to which they had agreed. Although the illustrators were asked to provide style samples during the planning phase of the books, this dilemma suggests that, for projects such as this, illustrators should be adequately prepared beforehand that the illustrations should reflect the authors' wishes and context rather than their own preferences. Feedback sessions proved to be valuable to the participants, illustrators, and facilitators, with all parties noting that it was a learning experience for them.

\section{Feedback after the project}

Feedback was collected from project participants, the community, and other beneficiaries after completion of the project. The discussion of participant and community feedback is followed by a discussion of how the books were used beyond the immediate scope of the project.

\section{Participant Feedback}

One parent noted that the wordless format allowed them to tell their own stories rather than just read what text was provided. Another adult participant (a sister to the child participant) said that reading was something they could do as a family now, and that each of them could tell their own story based on their individual interpretation of the illustrations.

Participants from both sites said that should the project run again, they would like to act as mentors to new project participants given that they had completed the project and could help other parents with the process. This was the case in Mamelodi in 2018, where participants from the 2017 project acted as mentors and helped facilitate story workshops. All participants suggested that the project be continued, one saying, "If you can get more kids and teachers to know about these kinds of books that can help our kids to use their imagination to tell a story." Some recommended involving the children more, whereas others believed that more parents in the community needed to become involved.

Feedback from the participants suggests that parents felt empowered by the project and have a vested interested in seeing it continue. Arguably, the most important part of the feedback is the impact that the process has had on how parents perceive themselves. A positive association with books and reading as an activity has the potential to change the reading environment at home and to cultivate a culture of reading in at least the participants' homes. 


\section{Feedback From the Community}

As noted earlier, feedback was also collected from members of the Mamelodi community who were not directly involved in the project. In total, 51 feedback forms were collected, although some of them were incomplete. A thematic analysis of the forms identified five predominant themes throughout the feedback, namely, ease of use, educational outcomes, positive parent-child experiences, imagination, and relatable content. These are discussed in turn below.

\section{Ease of use}

The majority of respondents indicated that the books were easy to use and interesting and that, in most cases, the child took the lead during the reading session. In some cases, there was a learning curve when using the books, with one respondent noting: "It was difficult when we started, but eventually we managed and started to have fun together." Other descriptions of the reading process included "It was fun for the child to use pictures to create a story," "It was easy," and "It was beautiful."

\section{Educational outcomes}

Many of the aspects that respondents liked about the books were linked to educational outcomes. Quotes such as "To teach my baby to learn more" and "They are educating our kids" were frequent. Other respondents highlighted the fact that the books did not rely on the decoding of words in quotes such as "Other books do not have pictures, so if you don't understand the words, then you are lost."

\section{Positive parent-child experiences}

Responses from the feedback forms frequently reported the use of the books as facilitating positive parent-child experiences. A further two subthemes emerged from this-firstly, the enjoyment of the parent-child interaction that was facilitated by these books. When responding to questions that pertained to what readers liked or disliked about the books, and whether they experienced reading with wordless picturebooks differently to reading other books with their child, responses that reported an improvement in parent-child relationship were frequent. One respondent noted, "We talk more. She is becoming open," and another described their experience of the books as "give[ing] us time to have bonding sessions with our children." Other quotes included "My relationship with my child has improved and [I experience] lots of love and happiness when I see my child busy with those books."

Secondly, there were frequent reports of how the parents facilitated and helped their child do something that they perceived as meaningful and constructive. One respondent noted, "It was fun ... encouraging the child to read. When I come back from work he reads by himself." Another mother reported, "I . . s see myself as a proud mother who give[s] my son knowledge of the things that matters most in life." Two responses were specifically about overcoming challenges associated with reading, in general, or the wordless books, specifically. One parent reported on the reading experience: "Although he is difficult, he loves to challenge me with pictures," while another described how she had worked to encourage her son to enjoy reading the books: "It [reading] gave me [a] hard time because my son doesn't want anything [to do] with the books. I worked hard to make him love them." Quotes such as this indicate that parents were able to tailor solutions to engage their children with the books despite some initial resistance. Modelling reading behaviour has important implications for reading; as Tiemensam (2009) noted: the "beliefs, attitudes, and expectations that parents or other caregivers hold regarding reading are likely to have an effect on children's attitude and motivation to read" ( $p$. 60). 
Although feedback was generally positive, it should be considered in the context of the research sites. Many parents do not own any books in their own homes. Therefore, the introduction of any bookswordless or not-may have been considered a positive experience.

\section{Imagination}

Apart from education, the opportunity for children to use their imagination was emphasised, with one respondent noting that she liked that fact that "children can use their imagination without being told that they are wrong, because the books have no words." Another reported: "These ones [wordless books] trigger your own imagination, rather than reading something that has been written." Children's creativity was also pointed out in responses such as "The child was very good and creative too. We both give different meanings to the pictures." In a few instances, suggestions were made that words should be added to the books.

\section{Relatable content}

It was clear from the feedback forms, that the content of the books was something with which the wider community could relate. One of the respondents said: "My images are beautiful, they look like when my father was farming or just busy with his garden." Another comment was about How to Brush Your Teeth and read: "How to Brush [Your] Teeth has a meaning [for us], especially when it is time to brush my teeth and hers" and "How to Brush Your Teeth has made me realise that in my culture they [say] young ones need not brush their teeth, but these books encourage the parents to look after their children's teeth."

Readers could recognise elements from their own background in the stories, as was evident in quotes such as "I think my mother should make a garden. I saw the stove that is similar to the one at home" and "Rainy Day reminds me of times when my grandmother taught me how to create my own garden and how to plough, plant and care for those plants from when they are still seedlings until we eat the produce." People noted enjoying the stories because they could relate to the people, for example, when asked why they enjoyed a specific book, responses included "Because my aunt is a dress maker" and "It reminded me of my father, he liked gardening." The ability for participants to create stories that were relevant to their own contexts and lives is significant given that Edwards and Ngwaru (2012) noted that children are not necessarily motivated to read for pleasure if reading materials have little or no relevance to their everyday life. Le Roux (2017) noted that the book "cannot become a cultural good until its contents are relevant and suitable to the culture in which it needs to establish importance" (p. 82).

Although the feedback on illustrations was generally positive, the study did not explore in detail how these were interpreted by different readers. Illustrations include signs and symbols that have different connotations in different cultures; consequently, the project will need to look at how the illustrations are interpreted by different audiences. At this stage of the project's development, it is expected that there would be misunderstandings or misrepresentations of contexts by the illustrators, who work in contexts different than those of the participants (authors). Future research needs to consider this and seek to gather feedback.

\section{Distribution and Use}

As mentioned previously, the books were not only circulated to participants and their community but also donated to schools, reading organisations, and other nonprofit organisations. Feedback was requested on how the books would be used, and is reported on below. 
One of the project books, Serepana, was used by SmartStart (https://www.smartstart.org.za), a nongovernmental organisation specialising in early childhood education, as a make-it-yourself book. The book was included as a cut-out in a newsletter that is circulated to roughly 2,500 trained practitioners of their programme, which reaches 3- and 4-year-old children who, previously, had no access to early learning. The Boys and The Library were converted into pullout books by Nal'ibali (https://www.nalibali.org/story-resources/multilingual-supplements), a national reading for enjoyment campaign, and printed in a number of South African newspapers for distribution.

Ten of the e-books were uploaded to the Worldreader (https://www.worldreader.org) mobile application, which gives readers access to digital books via e-readers and mobile phones and focuses on providing reading material to people in underserved communities. Because interpretation is left to the reader, stories created from the wordless picturebooks can be relevant to the perceptions of the reader. Such platforms are a valuable way of distributing books to communities, nonprofit organisations, and educational settings, and the adaptation of the project's books for use on this platform demonstrates how the results of a community-based research partnership can be extended to other, even global, communities.

Print files of the books were requested by a children's centre based in rural Lesotho. South African Sesotho differs from Lesotho Sesotho, and there are very few children's books available in the latter language. The centre has indicated that it can use the wordless format to encourage children to read without needing to translate any material. The books can be integrated into their learning projects or modified to suit their learning outcomes.

The books were also used in the creation of curriculum material for learners at 44 schools for the Deaf in South Africa ${ }^{5}$. The Deaf community of South Africa is ethnically and culturally diverse, and it is not easy to find story plots that are appropriate for the wide range of deaf learners. Feedback from Frenette Southwood, a researcher at Stellenbosch University involved in managing the project, noted that the wordless picturebooks were ideal in this regard; she said, "Not only are the stories conceptualised by South Africans, the illustrations are also appropriate for our context-the books are home-grown and relevant in every respect" (Personal correspondence, 15 January 2018). The illustrations were used as background in a DVD that features a story being told in sign language, and printed books are made available after the learners have watched the DVD.

\section{Limitations and Delimitations of the Study}

The sample size for the study is small, and findings cannot be generalised to the population. Although the feedback collected from the community (participants not directly involved in the book creation project) was positive, we acknowledge that the concept needs to be evaluated by a larger sample. Although participative research tries to foster equitable relationships between all parties involved, we acknowledge that the research process does have inherent "unevenness of power and ownership" (Burns, 2007, p. 138). For example, concept authors may still have felt that they could not change the illustrator (as expert)'s work, despite the project's efforts to circumvent such instances. Although issues of illiteracy play a major role in context of the study, literacy was not the focus of our research and we do not attempt to measure or report on changes in literacy.

\footnotetext{
${ }^{5}$ A project devised by the SASL Material Development Unit in the Department of General Linguistics at Stellenbosch University.
} 


\section{Conclusion}

Preliminary findings from the data show that there was a positive impact on the individuals involved. For example, the experiences described by parents and children engaged in the project led to a more positive engagement in, and perception of, book sharing, and positive changes in how parents perceived their abilities and their contribution to the lives of others. Given that social change begins with changes to individual behaviour, an experience such as this could create an entry point to positive book experiences and a love of reading being fostered in participant households.

The concepts and illustrations were easy to use in other formats. The adaptation of the books by other organisations demonstrates that a community-based research partnership can be extended beyond the initial scope of a project to facilitate change beyond one or two research sites. Feedback on the adaptation and use of the books has been given to the gatekeepers who disseminate the information to the concept authors. In this way, participants are able to see how their stories are impacting the lives of others.

There are, however, a number of details that need to be better considered in future projects - such as issues of authorship and understanding between illustrators and authors. These issues are being addressed and elaborated in a follow-up article that is currently under review.

Although this was a very small-scale project and the findings cannot be generalised, the feedback and use of the books in broader society suggest that a participatory model for creating relevant, local content for reading is not only viable but also valuable to communities and other stakeholders.

\section{Acknowledgments, Competing Interests, and Funding Information}

The authors would like to thank the project participants and illustrators. We also wish to extend our thanks to Elmien Claassens, Abigail Mzayidume, and Lelanie Steyn, who provided support in terms of hosting the project, reaching out to participants, and arranging the book launch celebrations.

The financial assistance of the National Research Foundation (NRF) towards this research is hereby acknowledged. Opinions expressed, and conclusions arrived at, are those of the authors and are not necessarily to be attributed to the NRF. The authors also gratefully acknowledge funding from corporate sponsors.

Adrie Haese is one of the directors of Collaborate Community Projects, the nonprofit/public benefit company through which this project was run. The company paid no director salaries for the duration of this project. Audited financial statements are available on request from the author.

\section{References}

Acker, T. (2012). The patterns of development in generated narratives of a group of typically developing South African children aged 5 to 9 years [Master's thesis, Stellenbosch University]. Semantic Scholar https://pdfs.semanticscholar.org/d1ab/5db26dda1d0428d3d7bf186b17c17f69ad05.pdf

Arbuckle, K. (2004). The language of pictures: Visual literacy and print materials for adult basic education and training (ABET). Language Matters, 35(2), 445-458. https://doi.org/10.1080/10228190408566228 
Arizpe, E. (2014). Wordless picturebooks: Critical and educational perspectives on meaning-making. In B. Kümmerling-Meibauer (Ed.), Picturebooks: Representation and narration (pp. 98-112). Routledge.

Arizpe, E., Colomer, T., \& Martínez-Roldán, C. (2014). Visual journeys through wordless narratives: An international inquiry with immigrant children and the arrival. Bloomsbury.

Bless, C., Higson-Smith, C., \& Sithole, S. L. (2013). The fundamentals of social research methods: An African perspective (5th ed.). Juta Books.

Braun, V., \& Clarke, V. (2013). Successful qualitative research: A practical guide for beginners. SAGE.

Burns, D. (2007). Systemic action research : A strategy for whole system change. Policy Press.

Crawford, P., \& Hade, D. (2000). Inside the picture, outside the frame: Semiotics and the reading of wordless picture books. Journal of Research in Childhood Education, 15(1), 66-80. https://doi.org/10.1080/02568540009594776

Dowhower, S. (1997). Wordless books: Promise and possibilities, a genre come of age. Yearbook of the American Reading Forum, XVII, 57-79. https://www.americanreadingforum.org/yearbook

Edwards, V., \& Ngwaru, J. M. (2012). African language books for children: Issues for authors. Language, Culture and Curriculum, 25(2), 123-137. https://doi.org/10.1080/07908318.2011.629051

eNCA. (2019, June 8). Reading skills crisis in South Africa [Video file]. eNCA. https://www.youtube.com/watch?v=EmKDpYhUFLo\&fbclid=IwAR1ek60CHwPHINLEqIURhD6COpeVKTgD4L6SocBSawi6wrijIrS3LHc6JI

Guba, E. G. (1981). Criteria for assessing the trustworthiness of naturalistic inquiries. ECTJ 29(75), 7591. https://doi.org/10.1007/BF02766777

Haese, A., Costandius, E., \& Oostendorp, M. (2018). Fostering a culture of reading with wordless picturebooks in a South African context. International Journal of Art and Design Education, 37(4), 587-598. https://doi:10.1111/jade.12202

Hjorton, U., \& Corneliuson, C. (2016). Foreword. In R. M. Lindfors, Silent books: A handbook on wordless picture books packed with narrative power. IBBY. https://www.ibby.org/fileadmin/user upload/Silent Books ENG.pdf

International Board on Books for Young People. (2020). Silent books. IBBY.

http://www.ibby.org/awards-activities/activities/silent-books/

Jalongo, M. R., Dragich, D., Conrad, N. K., \& Zhang, A. (2002). Using wordless picture books to support emergent literacy. Early Childhood Education Journal, 29(3), 167-177. https://doi.org/10.1023/A:1014584509011

Knudsen-Lindauer, S. L. (1988). Wordless books: An approach to visual literacy. Children' s Literature in Education, 19( 3 ), 136-141. https://doi.org/10.1007/BF01127091

le Roux, A. (2012). The production and use of wordless picturebooks in parent-child reading: An exploratory study within a South African context [Master's thesis, Stellenbosch University]. CORE. https://core.ac.uk/download/pdf/37348376.pdf

le Roux, A. (2017). An exploration of the potential of wordless picturebooks to encourage parent-child reading in the South African context [Doctoral dissertation, Stellenbosch University]. Sun Scholar. https://scholar.sun.ac.za/handle/10019.1/100920

Lindfors, R. M. (2016), Silent books: A handbook on wordless picture books packed with narrative power. IBBY. https://www.ibby.org/fileadmin/user upload/Silent Books ENG.pdf 
Mahala, S. (2010). Cultivating the culture of reading: An imperative for nation-building. Cape Librarian, 54(3), 12-13. https://www.westerncape.gov.za/newslettermagazine-issue/cape-librarian-vol-54-no-32010-05-01

Meiers, M. (2004). Reading for pleasure and literacy achievement. Research Developments, 12(12), Article 5. https://research.acer.edu.au/resdev/vol12/iss12/5

National Association for the Education of Young Children (NAEYC). (1998). Young Children, 53(4), 3046. https://www.jstor.org/stable/42728456

Nikolajeva, M., \& Scott, C. (2001). How picturebooks work. Garland Publishing.

Reese, C. (1996). Story development using wordless picture books. The Reading Teacher, 50(2), $172-$ 173. http://www.jstor.org/stable/20201735

Schaffer, A., \& Watters, K. (2003). Formative evaluation of the first phase of first words in print. Unpublished summary report.

Serafini, F. (2014). Exploring wordless picture books. The Reading Teacher, 68(1), 24-26. https://doi.org/10.1002/trtr.1294

Shenton, A. (2004). Strategies for ensuring trustworthiness in qualitative research projects. Education for Information, 22, 63-75. https://doi.org/10.3233/EFI-2004-22201

Singh, S., \& Wassenaar, D. R. (2016). Contextualizing the role of the gatekeeper in social science research. South African Journal of Bioethics and Law, 9(1), 42-46. https://doi.org/7196/SAJBL.465

Snow, C. E. (1991). The theoretical basis for relationships between language and literacy in development. Journal of Research in Childhood Education, 6(1), 5-10. https://doi.org/10.1080/02568549109594817

Spaull, N., van der Berg, S., Wills, G., Gustafsson, M., \& Kotzé, J. (2016). Laying firm foundations: Getting reading right. Final report to the ZENEX Foundation on Poor Student Performance in Foundation Phase Literacy and Numeracy. ZENEX Foundation.

Statistics South Africa. (n.d.). General household survey: Measuring the progress of development in the country-May

2019. http://www.statssa.gov.za/publications/P0318/GHS2018presentation \%20FinalforSG.pdf

Strickland, D., \& Riley-Ayers, S. (2006). Early literacy: Policy and practice in the preschool years. National Institute for Early Education Research Preschool Policy Brief. https://buildinitiative.org/Portals/0/Uploads/Documents/Early\%20Literacy\%20\%20Policy\%20and\%20Practice\%20in\%20the\%20Preschool\%20Years.pdf

Tiemensam, L. (2009). The literacy environment in support of voluntary reading: A case study in Gauteng East and Highveld Ridge area [Masters Dissertation, University of South Africa]. UNISA IR. http://hdl.handle.net/10500/1738

United Nations Educational Scientific and Cultural Organization (UNESCO). (2006). Education for all: Literacy for life. EFA Global Monitoring Report. UNESCO.

Williamson, M. M. (2016). A critical exploration of the role of pedagogical documentation in a multimodal Grade R classroom: A case study in an urban South African School [Master's thesis, University of the Witwatersrand].

http://wiredspace.wits.ac.za/jspui/bitstream/10539/22616/2/Morag\%20Williamson\%200208238 B\%20MEd\%20Dissertation.pdf 